\title{
Kan Grubu Farklılıkları Larinks Kanseri Gelişiminde Belirleyici Bir Faktör Olabilir Mi?
}

\author{
Can Abo Blood Grouping Be A Risk Factor For Laryngeal Cancer?
}

Hasan Çanakçı

Balıkesir Üniversitesi Tip Fakültesi Kulak Burun Boğaz Hastalıkları Anabilim Dalı, Balıkesir, Türkiye

Correspondence:

Hasan ÇANAKÇI

Balıkesir Üniversitesi Tip Fakültesi Kulak Burun Boğaz Hastalıkları Anabilim Dalı, Balıkesir, Türkiye e-mail:hsn_canakci@hotmail.com

\section{Özet}

Literatürde larinks kanseri ve kan grupları arasındaki ilişkinin araştırıldığı çalışmalarda tartışmalı sonuçlar mevcuttur. Çalışmamızın amacı kan grubu farklılıkları ve larinks kanser gelişim evreleri arasındaki olası ilişkinin incelenmesidir. Çalışmamıza 3. Basamak bir sağlık kurulușunda Kulak Burun Boğaz Hastalıkları ve Baş Boyun Cerrahisi Kliniğ̣inde 01 Ocak 2014- 31 Ekim 2020 yılları arasında, larinks patolojisi ön tanısı ile direkt laringoskopi altında biyopsi operasyonu geçirmiş olan 251 hastanın dosyaları geriye dönük olarak incelenmiștir. Hastaların yaş, cinsiyet, kan grubu verileri ve histopatolojik tanıları değerlendirilmiștir. Hastalar histopatolojik tanılarına göre \% 32,65 oranında benign (n:64), \%38,78 oranında premalign (n:76) ve \%28,57 oranında malign (n:56) laringeal lezyon olarak gruplandırılmıştır. Gruplar yaş açısından karşılaştırıldığında yaş ortalaması malign laringeal lezyon grubunda premalign laringeal lezyon grubundan, premalign laringeal lezyon grubunda da benign laringeal lezyon grubundan anlamlı şekilde yüksektir $(\mathrm{p}<0,001)$. Cinsiyet dağılımına bakıldığında erkek cinsiyet oranı malign laringeal lezyon grubunda premalign laringeal lezyon grubundan, premalign lezyon grubunda da benign laringeal lezyon grubundan anlamlı șekilde yüksektir $(\mathrm{p}<0,001)$. Gruplar arasında kan grupları açısından kıyaslama yapıldığında A kan grubu taşıyan hasta oranı malign laringeal lezyon ve premalign laringeal lezyon gruplarında benign laringeal lezyon grubuna göre anlamlı bir şekilde yüksek bulunmuștur (sırasıyla $\mathrm{p}=0,005, \mathrm{p}=0,025$ ). Diğer kan grupları dağılımında istatistiksel açsından anlamlı bir fark saptanmamıștır. Bu bulgularla larinks kanseri gelişimi sürecinde ya da tanılı hastaların takiplerinde A kan grubuna sahip bireylerin malignleşme potansiyellerinin daha fazla olabilme ihtimali sebebiyle yakın takip edilmesinin faydalı olacağını düşünmekteyiz.

Anahtar Kelimeler: Larinks kanseri; kan grubu; displazi; risk faktörü.

\section{Abstract}

There are controversial results in studies investigating the relationship between laryngeal cancer and blood group in the literature. The aim of our study is to examine the possible relationship between blood group and laryngeal cancer. 251 cases who had undergone direct laryngoscopy and biopsy with the diagnosis of laryngeal pathology, in the Department of Otorhinolaryngology and Head and Neck Surgery of a 3rd level healthcare institution in the period between January 01,2014 and October 31,2020 were analyzed. The age, gender, blood group and histopathological diagnosis of the cases were evaluated. According to their histopathological diagnosis, the cases were grouped as benign $(32,65 \%, \mathrm{n}: 64)$, premalignant $(38.78 \%, \mathrm{n}: 76)$ and malignant laryngeal lesion $(28.57 \%, \mathrm{n}: 56)$. When the groups were compared in terms of age, the mean age was significantly higher in the malignant laryngeal lesion group than in the premalignant group and in the premalignant laryngeal lesion group than in the benign group $(\mathrm{p}<0.001)$. Considering the gender distribution, male sex ratio was significantly higher in the malignant laryngeal lesion group than in the premalignant group, and in the premalignant lesion group compared to the benign group $(\mathrm{p}<0.001)$. When the blood groups were compared between the groups, the rate of te cases with blood group A was found to be significantly higher in the malignant laryngeal lesion and premalignant laryngeal lesion groups compared to the benign laryngeal lesion group $(\mathrm{p}=0.005, \mathrm{p}=0.025$, respectively). No statistically significant difference was found in the distribution of other blood groups. As a result, we think that the close follow up of the cases diagnosed premalign laryngeal lesions or laryngeal cancer with blood group A would be useful because of the high potential of the canserization of the cases wth the blood group A suffer from the laryngeal lesions.

Keywords: Larynx cancer; blood group; dysplasia; risc factors. 


\section{Giriş}

Baş boyun bölgesi kanserleri içerisinde en s1k karşılaşı1lan larinksin yassı hücreli karsinomu dünyada tüm kanser türleri içerisinde $\% 1-2$, baş boyun kanserleri içerisinde ise yaklaşı olarak \%20 sıklı̆̆ında görülmektedir (1). Türkiye sağlı istatistikleri 2016 verilerine bakıldığında ise larinks kanserinin görülme sıklığ 1 ülkemizde görülen tüm kanser türleri içerisinde \% 2,4'lük bir oran ile 9. sırada yer almaktadır (2).

Larinks kanseri gelişiminde en önemli risk faktörleri sigara ve alkol olarak gösterilmiştir. Bunu yanında erkek cinsiyet, düşük sosyoekonomik durum ve human papiloma virüs (HPV) varlığının da larinks kanserinde kanser gelişimi açısından anlamlı olduğu ortaya konmuştur (3-5). Bazı olgularda ise bu risk faktörleri bulunmamasına rağmen ileri evre larinks karsinomu ile karşılaşılabiliyor olunması farklı predispozan faktörlerin arayışına itmiştir. $\mathrm{Bu}$ bağlamda bireyler arasındaki en temel farklılıklardan olan kan gruplarındaki değişimlerin, bu kan grubunu taşıyan bireylerin farklı hastalıklara olan yatkınlıklarını artırabileceği veya tam tersi mantıkla hastalıklara karşı koruyucu bir rol oynayabilecekleri ileri sürülmüştür. Özellikle kan gruplarının dağılımlarının coğrafi bölgelere ve etnik gruplara göre farkl1l1k göstermesi ve bazı kan grubu antijenleri ile bazı kanser tipleri (mide, pankreas gibi) arasındaki ilişkinin ortaya konmuş olması son zamanlarda bu konuya olan ilgiyi arttırmıştır $(6,7)$.

Larinks kanseri ve kan grupları arasındaki ilk çalışma 1964 yılında yapılmıştır (8). Sonraki yılarda yapılan devam çalışmalarında kan grubu farklılıkları ve larinks kanseri arasındaki ilişkiye yönelik tartışmalı sonuçlar yayınlanmıştır $(3,4,9)$. Fakat literatür taramamızda Türkiye popülasyonu özelinde larinks hastalıklarında bening, pemalign ve malign oluşumlara göre kan grubu farklılıklarının incelendiği bir çalışma bulunamamıştır. $\mathrm{Bu}$ sebeplerden dolayı, bu çalışmada hastanemizde direkt laringoskopi ve biyopsi operasyonu sonrasi benign, premalign ve malign laringeal lezyon tanısı almış olan 251 hastanın geriye dönük incelenmesi yapılarak, $\mathrm{ABO}$ ve $\mathrm{Rh}$ grupları farklılıkları ve larinks kanser gelişim evreleri arasındaki olası ilişkinin incelenmesi amaçlanmıştır.

\section{Gereç ve Yöntemler}

Çalışmamıza 3. Basamak bir sağlık kuruluşunda Kulak Burun Boğaz Hastalıkları ve Baş Boyun Cerrahisi Kliniği'nde 01 Ocak 2014- 31 Ekim 2020 yılları arasında, 18-85 yaş aralığındaki, cinsiyet ayırımı yapılmadan, larinks patolojisi ön tanisı ile ile direkt laringoskopi altında biyopsi operasyonu geçirmiş olan hastalar dâhil edilmiştir. Larinks kanseri dişında ikincil malignitesi olan ya da metastatik laringeal lezyonu nedeniyle opere olan ve verilerinde eksiklik bulunan hastalar çalışma dışında bırakılmıştır.

Çalışma için referans merkez niteliğinde 3 . basamak hastaneden 27.01.2021 tarih ve 2021/23 karar numaras1 ile yerel etik kurul onayı alınmıştır. Çalışmamız Helsinki Deklarasyonu Prensipleri'ne uygun olarak yapılmıştır. Çalışmada verileri kullanılan hastalardan "Bilgilendirilmiş rıza (informed consent)" formu alınmıştır.

Çalışmaya dahil edilen hastaların demografik özellikleri (yaş, cinsiyet), ABO ve Rhesus (Rh) kan grupları ile postoperatif histopatolojik tanıları incelenmiş ve kayıt edilmiştir. Hastaların $\mathrm{ABO}$ ve $\mathrm{Rh}$ kan gruplar1; lam aglütinasyon, tüp aglütinasyon veya jel santrifügasyon yöntemi kullanılarak belirlenmiştir. Hastalar postoperatif histopatolojik tanılarına göre, vokal kord nodülü, polip, reinke ödemi, retansiyon kisti, granulom tanis1 alanlar benign laringeal lezyon (BLL); hiperplazi, keratozis, displazi ve karsinoma in situ tanısı konan hastalar premalign laringeal lezyon (PLL); invaziv karsinom tanisı alanlar ise malign laringeal lezyon (MLL) grubu olarak sınıflanmıştır (10).

Tüm istatistiksel analizler SPSS v 25.0 ile yapılmıştır. Grup verilerinin normallik varsayımı için kolmogorov smirnov testi kullanılmıştır. Sürekli değişkenler ortalama ( \pm standart sapma) olarak, kategorik değişkenler sayı ve yüzde olarak betimlenmiştir. Kategorik değişkenlerin 
gruplar arası s1kl1k verileri Ki-kare testi ve Fisher exact test ile karşılaştırılmıştır. Sürekli değişkenlerin gruplar arası karşılaştırmasında Kruskall Wallis testi ve Mann-Whitney U testi kullanılmıştır. $\quad \mathrm{P}<0,05$ değeri istatistiksel olarak anlamlı kabul edilmiştir.

\section{Bulgular}

Opere edilmiş olan 251 hastanın dosya incelemeleri sonrasında dişlama kriterlerine bağlı olarak ek malignitesi olan 5 hasta, metatastik laringeal lezyonu olan 5 hasta ve takip formlarında verilerinde eksiklik olan 45 hasta çalışma dışı bırakılmıştır. Çalışmaya dâhil edilen 196 hastanın ortalama yaş aralığı $57,01 \pm 12,24(\min : 27, \max : 85)$ ve $155 ' \mathrm{i}$ erkek $(\% 79,08), \quad 41$ 'i $(\% 21,92)$ ise kadın olarak saptandi. Postperatif histopatolojik tanılarına göre BLL grubunda64 $(\% 32,65)$, PLL grubunda $76(\% 38,78)$ ve MLL grubunda ise $56(\% 28,57)$ hasta mevcuttu. Hastaların ayrintılı taniları tabloda özetlenmiştir (Tablo 1).

Tablo 1: Hastaların histopatolojik tanılarına göre gruplandırılması

\begin{tabular}{|c|c|c|c|c|c|c|c|c|}
\hline BLL & $\mathbf{n}$ & $\%$ & PLL & $\mathbf{n}$ & $\%$ & MLL & $\mathbf{n}$ & $\%$ \\
\hline Polip & 42 & 65,62 & $\begin{array}{l}\text { Hafif } \\
\text { Derece } \\
\text { Displazi }\end{array}$ & 41 & 53,98 & $\begin{array}{l}\text { Skuamöz } \\
\text { Hücreli } \\
\text { Karsinom }\end{array}$ & 56 & 100 \\
\hline Reinke ödemi & 7 & 10,94 & $\begin{array}{l}\text { Ağır } \\
\text { Derece } \\
\text { Displazi }\end{array}$ & 35 & 46,02 & & & \\
\hline Kist & 6 & 9,37 & & & & & & \\
\hline Granülom & 3 & 4,69 & & & & & & \\
\hline Nodül & 2 & 3,13 & & & & & & \\
\hline $\begin{array}{l}\text { Fibrokollajenoz doku } \\
\text { artışı }\end{array}$ & 2 & 3,13 & & & & & & \\
\hline Miksoma & 1 & 1,56 & & & & & & \\
\hline Kavernöz Hemanjioma & 1 & 1,56 & & & & & & \\
\hline Toplam & 64 & 35,65 & & 76 & 38,78 & & 56 & 28,57 \\
\hline
\end{tabular}

BLL: Benign laringeal lezyon. PLL: Premalign laringeal lezyon. MLL: Malign laringeal lezyon

Hastaların yaş dağılımına bakıldığında MLL grubu yaş ortalaması PLL grubundan, PLL grubu yaş ortalaması da BLL grubundan anlamlı bir şekilde yüksektir $(\mathrm{p}<0.001)$. Cinsiyet dağılımında ise MLL ve PLL gruplarında BLL grubuna göre erkek cinsiyet anlamlı bir şekilde yüksek iken $(\mathrm{P}<0.001)$ MLL ve PLL grupları arasinda anlamlı bir fark yoktur $(\mathrm{p}=0,093) \quad($ Tablo 2). 
Tablo 2: Gruplardaki hastaların demografik verilerinin karşılaştırılması

\begin{tabular}{|c|c|c|c|c|c|}
\hline & & BLL & PLL & MLL & $p$ \\
\hline Cinsiyet: & & n (\%) & n $(\%)$ & n $(\%)$ & \\
\hline & $\begin{array}{l}\text { Erkek / } \\
\text { Kadın }\end{array}$ & $\begin{array}{l}37(\% 5,81) / \\
27(\% 42,19)\end{array}$ & $\begin{array}{l}65(\% 85,53) / \\
11(\% 14,7)\end{array}$ & $\begin{array}{l}53(\% 94,64) / \\
3(\%, 36)\end{array}$ & $\begin{array}{l}\mathbf{p}<\mathbf{0 , 0 0 1}{ }^{*} \\
\mathbf{p}<\mathbf{0 , 0 0 1} * * \\
\mathrm{p}=0,093 * * *\end{array}$ \\
\hline Yaș (ort+ss) & & $49.25 \pm 10.596$ & $58.12 \pm 11.722$ & $64.36 \pm 9.413$ & $\mathrm{p}<0,001$ \\
\hline
\end{tabular}

Gruplar arasında kan gruplarının dağılımına bakıldığında BLL grubunda en sık görülen $\mathrm{O}$ kan grubu $(\% 43,75)$ iken PLL ve MLL gruplarında en sik görülen kan grubu A kan grubudur (sirasiyla $\% 46,05$ ve \%42,9). Gruplar arasında kan grupları açısından kıyaslama yapıldığında A kan grubu taşıyan hasta oranı PLL ve MLL gruplarında BLL grubuna göre anlamlı bir şekilde yüksek bulunmuştur (sırasiyla $\mathrm{p}=0,005, \mathrm{p}=0,025)$ (tablo 4). PLL ve MLL grupları arasinda ise A kan grubu sıklığı açısından gruplar arasında anlamlı bir fark saptanmamıştır $(\mathrm{p}=0,715)$. Diğer kan gruplarının ( $\mathrm{B}, \mathrm{AB}, \mathrm{O}$ ve $\mathrm{Rh})$ gruplar arasındaki dağılım sıklıkları arasında ise anlamlı bir fark saptanmamıștır $(p>0,05)$ (Tablo 3).

Tablo 3. Gruplardaki hastaların kan grubu dağılımları

\begin{tabular}{|c|c|c|c|c|}
\hline & BLL & PLL & MLL & $p$ \\
\hline Kan Grubu & n (\%) & n (\%) & n (\%) & \\
\hline $\mathbf{A}$ & $15(\% 23,44)$ & $35(\% 46,05)$ & $24(\% 42,9)$ & $\begin{array}{l}\mathbf{0 , 0 0 5} * \\
\mathbf{0 , 0 2 5} * * \\
0,715 * * *\end{array}$ \\
\hline B & $12(\% 18,75)$ & $15(\% 19,74)$ & $7(\% 12,5)$ & $\begin{array}{l}0,883 * \\
0,349 * * \\
0,270 * * *\end{array}$ \\
\hline $\mathbf{O}$ & $9(\% 14,06)$ & $4(\% 5,26)$ & $4(\% 7,1)$ & $\begin{array}{l}0,074 * \\
0,224 * * \\
0,722 * * *\end{array}$ \\
\hline AB & $28(\% 43,75)$ & $22(\% 28,95)$ & $21(\% 37,5)$ & $\begin{array}{l}0,069 * \\
0,487 * * \\
0,3 * * *\end{array}$ \\
\hline $\begin{array}{l}\mathbf{R h}(+) / \\
\operatorname{Rh}(-)\end{array}$ & $\begin{array}{l}56(\% 87,5) / \\
8(\% 12,5)\end{array}$ & $\begin{array}{l}68(\% 89,47) / \\
8(\% 10,53)\end{array}$ & $\begin{array}{l}52(\% 92,86) / \\
4(\% 7,14)\end{array}$ & $\begin{array}{l}0,715^{*} \\
0,329 * * \\
0,604 * * *\end{array}$ \\
\hline
\end{tabular}

BLL: Benign laringeal lezyon. PLL: Premalign laringeal lezyon. MLL: Malign laringeal lezyon.

*: BLL-PLL karşılaştırmasıl, **: BLL-MLL grubu karşılaştırması, ***: PLL-MLL karşılașstırması.

$P<0,05$ anlamlı kabul edilmiştir. İstatistiksel açıdan anlamlı olan $p$ değerleri kalın olarak işaretlenmiştir.

\section{Tartışma ve Sonuç}

Baş boyun kanserleri dünyada tüm kanser tipleri arasında 6. sıklıkta karşımıza çıkmaktadır. Baş boyun kanserleri içerisinde en sik karşılaşılan kanser ise larinks kanseridir(4,11). 2017 yılında dünya çapında toplam 210.606 yeni larinks kanseri olgusu teşhis edilmiştir (2.76/100.000). Aynı y1lda prevelans 1.09 milyon olgu (14.33/100.000), ölüm sayıs1 $126.471 \quad(1.66 / 100.000)$ olarak kayıtlara geçmiştir. Son 30 yıldaki 
istatistikler incelendiğinde ise larinks kanseri tanısının insidans ve prevalans sirasıyla \% 12,0 ve $\% 23,8$ artarken, mortalite yaklaş1k \% 5 azalmıştır (12). $\mathrm{Bu}$ tanı konulma sıklığındaki artışla ters orantılı olarak mortalite sıklığındaki azalışta en önemli parametrelerden birisi, hastalığın erken teşhisi ve özellikle tedavi seçeneklerindeki ilerlemedir. Bunun yanında larinks kanserinde özellikle yüksek risk altındaki popülasyonlarda, prognostik kriterlerin tayini, hastalık progresyonunu önleyici tedbirlerin alınması ve özellikle hastaların yakın takibi kanserin tedavisinde yüz güldürücü sonuçlar vermektedir (1). Dolayısiyla her hastalıkta olduğu gibi larinks kanserinde de özellikle hastalık progresyonu ve prognozunda önemli olan risk faktörlerinin aydınlatılması önem arz etmektedir.

Larinks kanserinin gelişiminde sigara ve alkol başta olmak üzere erkek cinsiyet, ileri yaş ve düşük sosyoekonomik durum gibi birçok etken larinks kanserinin artmış insidansı ile yakın ilişkili bulunmuştur. Risk faktörlerinin ortadan kaldırılması ile hastalık gelişiminde \%90'a varan oranlarda azalma olabileceği bildirilmiştir (13-15). Sigara ve alkol dışında herpes simplex virüs ve human papilloma virüs enfeksiyonları, sicak buhar inhalasyonu, gastroözefageal reflü hastalığı, termal yanıklar, iyonize radyasyona maruziyet, asbestozis, nikel, tekstil ürünleri, formaldehit, vinil klorid ve benzopiren gibi çeşitli kimyasallar ve kan grubu farklılıklarının da larinks kanser gelişiminde etiyolojik risk faktörü olduğuna yönelik görüşler öne sürülmüştür $(3,4,9)$. Çalışmamızda yukarıda bahsi geçen risk faktörleri içerisinde erkek cinsiyet ve yaş ortalaması literatür bulguları ile uyumlu bir şekilde MLL ve PLL grubunda anlamlı olarak yüksek bulunmuştur $(\mathrm{MLL}>\mathrm{PLL}>\mathrm{BLL})(3)$.

Çalışmamızın birincil amacı olan kan grubu farklılıklarının laringeal lezyonlar üzerindeki etkisinin incelenmesi, her hastalık özelinde olduğu gibi hastaların bu hastalığ geliştirmesinde etkili olabilecek ana farklılıklarının saptanması amaciyla gerçekleşmiştir. ABO kan grubu sistemi, 9q34.2 lokalizasyonunda haritalandırılmış olup eritrositlerin yüzeyindeki, hücre membranının yapısal bütünlüğünün sağlanması, membrandan molekül transportu ve adezyon gibi fonksiyonlara sahip olan protein ve karbonhidrat içeren A veya B kan grubu antijenlerinin varlığına göre belirlenmektedir. $(3,16,17)$. Ayrica kan grubu antijenlerinin dağılımının coğrafi bölgelere ve etnik kökenlere göre farklılık gösterdiği bilinmektedir. $\mathrm{Bu}$ bağlamda Türkiye genelinde kan grubu dağılımına bakıldığında A kan grubu \% 42,84 oranı ile en sık görülen kan grubudur. İkinci sirada $\mathrm{O}$ kan grubu $(\% 32,67)$ görülürken, en az görülen kan grubu AB'dir $(\% 8,03)$ (18). Amerika'da ise bu dağılım oranları incelediğinde, etnik gruplara göre değişmekle birlikte en s1k görülen kan grubunun $\mathrm{O}$ kan grubu olduğu görülmüştür $(\% 46,7)(18,19)$.

$\mathrm{ABO}$ antijenleri insan vücudunda eritrositler ile birlikte epitelyal ve endotelyal hücrelerde de exprese edilerek hücre diferansiyasyonu ve maturasyonunun düzenlenmesinde rol almaktadır (20-22). Bu perspektiften bakıldığında Alexzender ve ark. tarafindan 1921 y1lında ABO farkl11kkları ile tömörogenez arasında bir ilișki olabileceği öne sürülmüş olup sonraki çalışmalarda bu mekanizmada A ve B grup antijen sisteminin yerleşik olduğu 9q34.2 genomundaki bozulmanın ve buna bağlı olarak antijen ekspresyonundaki bozulmanın normal hücreden maligniteye progresyonda anlamlı değişimler olduğu, hücresel hareketliliğin arttığı ve tümöral hücreler ile uzak organ endotel hücreleri arasındaki etkileşimin kolaylaştığı ortaya koyulmuştur $(4,17,23,24)$. Ayrica tümörogeneziste hücre yüzeyi karbonhidrat yapısı ile $\mathrm{ABO}$ kan grubu antijenleri karbonhidrat yapılarındaki sentez ve ekspresyon değiștiği ve bu karbonhidratprotein etkileşiminin hücreler arası adezyonda ve tümör metastazında rol oynayabileceği gibi görüşleri destekleyen çalışmalar yapilmıştır. (25).

Literatür taramamıza göre larinks kanseri ile kan grubu arasındaki ilişkinin ise ilk olarak 1964'te Celestino D ve ark. tarafindan incelendiği ve anlamlı bir ilişki olmadığının raporlandığ 1 görülmüştür (8). Bu çalışmaya benzer şekilde Novinska E ve ark. kan grubu antijen ekspresyonunun larinks kanserinde risk faktörü olmadığını raporlamışlardır. (26). Adam ve ark. 143 larinks kanseri tanılı hasta 
ile yaptıkları çalışmada A kan grubunun Afroamerikan hastalarda beyaz tenli Amerikalılara oranla daha sik oranda bulunduğunun saptanmasina rağmen tüm hastalar değerlendirildiğinde kan grubu ve larinks kanseri arasında istatistiksel olarak anlamlı bir fark olmadığını raporlamışlardır(4). Bu çalışmaların aksine Jin ve ark. tarafindan Çin popülasyonunda yapılan ve Abd El Aal MS ve ark. tarafindan Mısır popülasyonunda yapılan çalışmalarda $\mathrm{O}$ $\mathrm{Rh}(+)$ kan grubunun larinks karsinomunda risk faktörü olduğu bildirilmiştir $(3,9)$. Burada muhtemel mekanizma olarak genotiplendirme ile $\mathrm{ABO}$ genindeki ilk introna denk gelen nükleotid polimorfizmi ile kanserleşme arasındaki güçlü ilişkiye yer verilmiş olup altta yatan moleküler ve patojenik farkl111kların $\mathrm{ABO}$ kan grubunun kanser üzerindeki etkisinde önemli rolü olabileceği vurgulanmıştır (3). Roa MSS ve ark. ile Singh $\mathrm{K}$ ve ark. tarafindan Hindistan'da yapilan çalışmalarda ise larinks kanseri olanlarda B $\mathrm{Rh}(+)$ kan grubunun daha yüksek oranda olduğu gösterilmiştir $(27,28)$.

Literatürdeki tartışmalı sonuçlara binaen kan grubu ve larinks kanseri arasındaki ilişkinin incelendiği çalışmalarda bölgesel etnik farkl11ıklara göre farklı sonuçlar raporlanmıştır. Fakat bahsi geçen çalışmalarda ve bizim literatür taramamıza göre, larinks kanserinin öncüsü olarak bilinen ve bazı çalışmalarda \%30'a varan oranlarda invaziv kansere dönüşümün gösterilmiş olduğu. premalign laringeal lezyonlarla, kan grubu farklılıkları arasındaki ilişkinin incelendiği çalışmalara rastlanmamıştır (29). Ayrıca, literatürde Türk insanında kan grubu dağılımına göre larinks kanseri veya premalign laringeal lezyonların insidansı ile ilgili bir çalışma da bulunmamaktadır. Coğrafik bölge ve etnik kökene göre kan grubu dağılımında farklılık düşünüldüğünde çalışmamız Türkiye'de Marmara bölgesi özelinde yürütülmüş ilk çalışma olma

\section{KAYNAKLAR}

1. Kum RO, Ozcan M, Baklaci D, Kum NY, Yilmaz YF, Gungor V, et al. Elevated neutrophil-tolymphocyte ratio in squamous cell carcinoma of larynx compared to benign and precancerous laryngeal lesions. Asian Pac $J$ Cancer Prev 2014;15:7351-5. özelliğindedir. Çalışmamızın verilerine göre PLL ve MLL tanisı alan hastalarda BLL tanisı alan hastalara oranla istatistiksel olarak A kan grubu sıklığının yüksek olduğu saptanmıştır. Kan grubu A olan bireylerde hücre yüzeyinde eksprese edilen A benzeri antijen (Forssmann veya $T n$ antijen), malign hücrelerde de tespit edilmektedir. Kan grubu $\mathrm{B}$ ve $\mathrm{O}$ olan kişilerde ise A-antikoru ekspresyonu mevcut olup bu antikorun A benzeri antijen taşıyan premalign veya malign hücreler ile etkileşime girerek bu hücrelerin ölmesine neden olduğu raporlanmıştır (30). Bu bağlamda A kan grubuna sahip bireylerde laringeal lezyonlarda malignite gelişme olasılığının daha yüksek oluşu premalign ve malign hücrelerde eskprese edilen A benzeri antijene karş1 antikorların bulunmaması ile açıklanabilir. Ayrica baş boyun kanserlerinde özellikle oral kavite kanserlerinde koruyucu rolü olduğu raporlanmış olan $\mathrm{H}$ antijeninin A kan grubuna sahip kişilerde eksprese edilmeyişinin (28). laringeal lezyonlar açısından A kan grubuna sahip hastalardaki yüksek malignite riski ile ilişkili olabileceğini düşünüyoruz.

Çalışmamız pilot çalışma olduğundan tek merkezli olup hasta sayısının az olması, retrospektif dizaynı sebebiyle yaş, cinsiyet ve kan grubu dışındaki risk faktörlerinin araştırılamamış olması ve hasta sayısındaki k1sitl111k sebebiyle BLL, PLL ve MLL lezyonlarının progresyonları hakkındaki değerlendirilmenin yapılamamış olması bu çalışmamızın kısıtlayıcı taraflarıdır.

Sonuç olarak, Türkiye'de Mamara bölgesinde Balıkesir ilinde yapılmış çalışmamızda lareingeal lezyonlar açsından bakıldığında MLL ve PLL hastalarında A kan grubuna sahip bireylerin istatistiksel olarak daha fazla sayıda yer aldığı gösterilmiştir. Bu bulgularla larinks kanseri gelişimi sürecinde ya da tanılı hastaları takiplerinde A kan grubuna sahip bireylerin malignleşme potansiyellerinin daha fazla olabilme ihtimali sebebiyle yakın takip edilmesinin faydalı olacağını düşünmekteyiz.

2. Kara F, Keskinkılıç B, Türkiye Kanser isatistikleri 2016, Halk Sağlığ1 Genel Müdürlüğü, Sağlık Bakanlığı, Ankara, 2019.

3. Jin $\mathrm{T}, \mathrm{Li} \mathrm{PJ}$, Chen XZ, Hu WH. ABO blood group is a predictor of survival in patients with laryngeal cancer. Chin J Cancer. 2016; 35: 90. 
4. Adam SI, Wilson KM, Overholser SM, et al. Are laryngeal squamous cell carcinoma incidence and patient mortality a function of $\mathrm{ABO}$ blood grouping? A retrospective study. J Laryngol Otol. $2012 ; 126: 180-4$

5. Li X, Gao L, Li H, Gao J, et al. Human papillomavirus infec- tion and laryngeal cancer risk: a systematic review and meta-analysis. $J$ Infect Dis. 2013;207:479-88.

6. Edgren G, Hjalgrim H Rostgaard K, et al. Risk of gastric cancer and peptic ulcers in relation to ABO blood type: a cohort study. Am J Epidemiol. 2010;172:1280-5.

7. Zhang BL, He N, Huang YB, Song FJ, Chen $\mathrm{KX}$. ABO blood groups and risk of cancer: a systematic review and meta-analysis. Asian Pac J Cancer Prev. 2014;15:4643-50

8. Celestino D, Silvagni C. On the distribution of blood groups of ABO system in individuals with laryngeal carcinoma. Valsalva 1964;40:211-6

9. Abd El Aal MS., Mohammed Roushdy MM., Mohamed El-Naggar, MS. Abd Allah Hussein, AA. ABO grouping as a risk factor for cancer larynx. EJNSO. 2020; 6: 20-6.

10. Gale N, Poljak M, Zidar N. Update from the 4th edition of the World Health Organization Classification of head and neck tumours: what is new in the 2017 WHO blue book for tumours of the Hypopharynx, Larynx, Trachea and Parapharyngeal Space. Head Neck Pathol. 2017; 11:23-32

11. Haddad RI, Shin DM. Recent advances in head and neck cancer. $N$ Engl J Med, 2008;359: 114354

12. Nocini R, Molteni G, Mattiuzzi C, Lippi G.Updates on larynx cancer epidemiology.Chin J Cancer Res. 2020 ;32:18-25.

13. Koyanagi YN, Matsuo K, Ito $\mathrm{H}$, et al. Cigarette smoking and the risk of head and neck cancer in the Japanese population: a systematic review and meta-analysis. Jpn J Clin Oncol. 2016;46:580-95.

14. Licitra L, Bernier J, Grandi C, et al. Cancer of the larynx. Crit Rev Oncol Hematol. 2003;47:65-80.

15. Altieri A, Bosetti C, Talamini R, et al. Cessation of smoking and drinking and the risk of laryngeal cancer. Br J Cancer. 2002;87:1227.

16. Reid ME, Mohandas N. Red blood cell blood group antigens: structure and function. Semin Hematol. 2004;41:93-117.

17. Mansour AH, Mohammed AM, Anwar R, et al. $\mathrm{ABO}$ blood group and risk of malignancies in Egyptians. International $J$ of Cancer Research 2014;10:81-95.

18. Ozkasap S, Dereci S, Sahin K, et al. Analysis of $\mathrm{ABO}$ and $\mathrm{Rh}$ blood groups distribution in East Karadeniz region of Turkey. Dicle Med. 2013; 40 : 100-4.

19. Garratty G, SA, McEntire R ABO and $R h(D)$ phenotype frequencies of different racial/ethnic groups in the United States. Transfusion. 2004 May;44:703-6.

20. Ravn V, Dabelsteen E. Tissue distribution of histo- blood group antigens. APIMS 2000;108:128.
21. Strauchen JA, Bergman SM, Hanson TA. Expression of $\mathrm{A}$ and $\mathrm{B}$ tissue isoantigens in benign and malignant lesions of the breast. Cancer. 1980;45:2149-55.

22. Schuessler MH, Pintado S, Welt S, Real FX, Xu $\mathrm{M}$, Melamed MR, et al. Blood group and blood-group-related antigens in normal pancreas and pancreas cancer: enhanced expression of precursor type 1, Tn and sialyl-Tn in pancreas cancer. Int J Cancer. 1991;47:180-7.

23. Kumar T, Puri G, Laller S, Bansal T, Malik M. Association of ABO blood grouping with oral lichen planus. Univ Res J Dent. 2014;4:93-6.

24. Guleria K, Singh HP, Kaur H, et al. ABO blood groups in gastrointestinal tract and breast carcinoma patients. Anthropologist 2005;7:18992.

25. Dabelsteen E. Cell surface carbohydrates as prognostic markers in human carcinomas. J Pathol 1996;179:358-69.

26. Nowinska E, Namyslowski G, Scierski W, Kocierz S. ABO blood groups in patients with laryngeal cancer (in Polish). Otolaryngol Pol 2000;54:209-11.

27. Rao MSS, Abraham TT. A retrospective study of blood groups in head and neck malignancies. $J$. Evid. Based Med. Healthc. 2018; 5, 908-12.

28. Singh K, Kote S, Patthi B, et al. Relative Risk of various head and neck cancers among different blood groups: an analytical study. J Clin Diagn Res 2014;8:ZC25-8.

29. Sadri M, McMahon J, Parker A. Management of laryngeal dysplasia: a review. Eur Arch Otorhinolaryngol. 2006;263:843-52.

30. Marionneau S, Moullac-Vaidye LM, Pendu JL. Expression of histo-blood group A antigen increases resistance to apoptosis and facilitates escape from immune control of art colon carcinoma cells. Glycobiology 2002;12:851-56. 